\title{
Differences in Architects and Nonarchitects' Perception of Urban Design: An Application of Kansei Engineering Techniques
}

\author{
Carmen Llinares, Antoni Montañana, and Elena Navarro \\ Escuela Técnica Superior de Ingeniería en la Edificación, Universitat Politècnica de València, Camino de Vera, s/n, \\ 46022 Valencia, Spain \\ Correspondence should be addressed to Carmen Llinares, cllinare@omp.upv.es
}

Received 7 June 2011; Accepted 22 September 2011

Academic Editor: Annette Hastings

Copyright ( $\odot 2011$ Carmen Llinares et al. This is an open access article distributed under the Creative Commons Attribution License, which permits unrestricted use, distribution, and reproduction in any medium, provided the original work is properly cited.

\begin{abstract}
We analyse architects and nonarchitects' emotional assessments of different districts in their own city (Valencia, Spain) by applying Kansei engineering techniques. A field study was carried out on a sample of 140 subjects (70 architects and 70 nonarchitects) who were asked to express their opinions on different areas in the city. The set of emotional impressions used by architects and non-architects to describe their sensations was obtained using differential semantics. The semantic space was described by 9 independent axis which explained $62 \%$ of the variability. Then, for each collective the set of impressions which influence the final residential or investment area decision was analysed. This relationship was obtained applying linear regression models. The results showed no significant differences between both groups so that the emotional attributes determining the choice of area were very similar for architects and non-architects. Greater discrepancies were found when the purpose of the choice was investment and not residential. Finally a neighbourhood was semantically profiled to represent and compare both collectives' perceptions.
\end{abstract}

\section{Introduction}

There are many studies on the differences in architects and nonarchitects' evaluations [1-13]. Some studies have analysed the categories that both collectives use when assessing buildings. Groat [2], for example, studied the differences in architects and economists' perceptions and found that while economists classified housing on the basis of type, architects used quality of design, form, style, and historical significance categories. In this regard, in an analysis of two office blocks in Chicago, Devlin [7] observed that whereas nonarchitects tended to give descriptive assessments based on affection, architects provided conceptual, more abstract assessments.

Other studies have focused on the different assessments of architectural styles. Gans [1] observed that architects preferred "high" style over "popular", the style preferred by nonexperts. Subsequently, Devlin and Nasar [6] concluded that this was due to the different emotional assessments which the styles caused in both collectives. For nonexperts the "popular" style was coherent, pleasurable, and clean, signifiers which architects attributed to the "high" style.
Fewer works have attempted to identify what specific design elements cause the different assessments. In this regard, Gifford et al. [11] analysed the relationship between the physical characteristics of buildings, the perceptions "attractive" and "pleasurable," and the subject's overall assessment, taking Brunswik's [14] lens model as the framework. In this study, architects and non architects had to assess 42 office buildings. The results showed that both groups based their emotional assessments on totally different features of the buildings.

Two basic causes were noted as determinants for the different assessments, different personality factors, and different knowledge structures. In relation to personality factors, it seems that enterprising, daring individuals who seek new sensations prefer the "high" style while individuals with a low level in this personality factor prefer the "popular" style $[6,15,16]$. Different knowledge structure is the second cause of divergence between both collectives [17-19]. Experience of our surroundings consists in repeat encounters of different examples forming the basis of an unconscious learning process for the individual [20] which is used to build a mental 
representation of preferred standards. These authors consider that observer preferences for buildings depend on the level of discrepancy between the type of building to be evaluated and the observer's knowledge structure. Thus, when an example coincides with the existing knowledge structure, it is a good or typical example. This may be associated with the "familiarity" concept [21]. In contrast, when an example differs greatly from the existing knowledge structure, it is an atypical or unfamiliar example. Two types of similarities and differences can be found in terms of experience in the groups, differences associated to geographical location and education. In terms of location, groups living in different geographical may not be exposed to the same types of examples. Consequently, what is familiar or typical in one location may be more or less familiar or atypical in another. Education can cause a group to have a greater perception of variations between architectural features. Students on a degree course in architecture are exposed to special examples of historic buildings, works by other architects, and, in short, to buildings which stand out from the typical buildings in the surrounding environment. Thus, for example, Akalin et al. [13] found differing opinions between architecture and engineering undergraduates on house facades from five housing sites. The students of architecture were more critical than the engineering students. Thus, architects and non architects resident in an area may initially share a knowledge structure based on an experience of the surrounding area, but as a result of their training, architects also have experiences of different examples. Architects' generic knowledge structure will change as they are exposed to a greater range of examples with differences in comparison to the existing knowledge structure.

Although there are many examples in the literature of both groups' different assessments of buildings, no studies have been found which analyse these differences in terms of urban design and more specifically in the choice of a certain residential environment. Dieleman and Mulder [22] define residential choice as a joint choice: "choice of a certain type of housing and a choice of a certain residential environment". According to residential search theories, people limit their search for housing to a certain location that complies with their situational needs [23]. The consequences of the choice of location, neighbourhood, or area in which to live are significant. Where one lives determines not only comfort, cleanliness, and security but also the quality of life, such as choice of education, career, and mate $[24,25]$.

Our question then is how are such preferences arrived at? The theory proposed by Brunswik in 1956 suggested that the relational process between the stimulus and the opinion or judgment emitted by the subject was an indirect one. Applied to the sphere of urban design, this approach assumes that subjects respond to the particular characteristics of the physical environment, integrate these reactions into emotional impressions, and transfer those emotional impressions to an aesthetic evaluation of the street or neighbourhood as a whole. This indirect assessment process has also been proposed by other evaluation models developed in very different areas. Thus, Kansei Engineering, developed in the area of user-oriented products design, attempts to identify and quantify users' perceptions of a product in their own language and to find quantitative relationships between these subjective responses and design features [26, 27]. Following this methodology, the first phase is to obtain the set of independent concepts (semantic axes or semantic space) which the user uses to describe his sensations in relation to the product. This semantic space forms an important tool for measuring an independent product or comparing different products from the perspective of their symbolic attributes.

Although scarce, the literature does offer some studies which determine the emotional reactions, subjective attributes, or semantic axes which are relevant in the evaluation of residential environments. Thus, Lynch [28] established that a "good city form" is vital, sensible, well fitted, accessible, and well controlled. Appleyard [29] determined that residents structured their values of a street in four principal dimensions: the street as sanctuary (clean, quiet, maintained, attractive, safe), child-rearing, accessibility, and neighbourhood identity. Jarvis [30] found opposing qualities of desirable places to live: convenience-separation; relatedness identity; affordability-luxury; tradition-innovation; unity-variety and safety-excitement. Küller [31,32] determined eight perceptual qualities as a means to characterizing architecture and the built environment: pleasantness, complexity, unity, enclosedness, potency, social status, affection, and originality.

Following this outline, this study aims to analyse the different perceptions in the collective of architects and non architects in the decision to choose an area. This was done by carrying out the first phase of Kansei methodology to analyse both collectives' emotional responses to the neighbourhoods in a city. Specifically, the study aims to: (a) quantify the difference between the opinions in both groups on choice of an area. We felt it was relevant to analyse the differences in relation to the purpose of the choice, residential or investment purposes. This aspect has not been studied so far in the area of perception, and it seems interesting to analyse whether the decision to reside or invest in an area depends on different symbolic aspects or attributes for each collectives (b) select relevant words, with as few words as possible to describe the semantic space for neighbourhoods, (c) order the set of emotional attributes in relation to their influence on the choice of an area as a place to live or invest, and (d) describe for both collectives the perceived images of a neighbourhood in relation to the rest of the city.

The results of this study could be used in future studies to determine what specific features or services should be present in a neighbourhood in order to create a certain impression.

\section{Materials and Methods}

The study was carried out in the city of Valencia (Spain) (Figure 1). As in other Spanish cities, Valencia has recently seen significant urban development. All the neighbourhoods within the metropolitan area were analysed according to the classification established by the City Council.

2.1. Subjects. The sample comprised 140 subjects, 70 architects, and 70 nonarchitects; all staff from the Universidad 


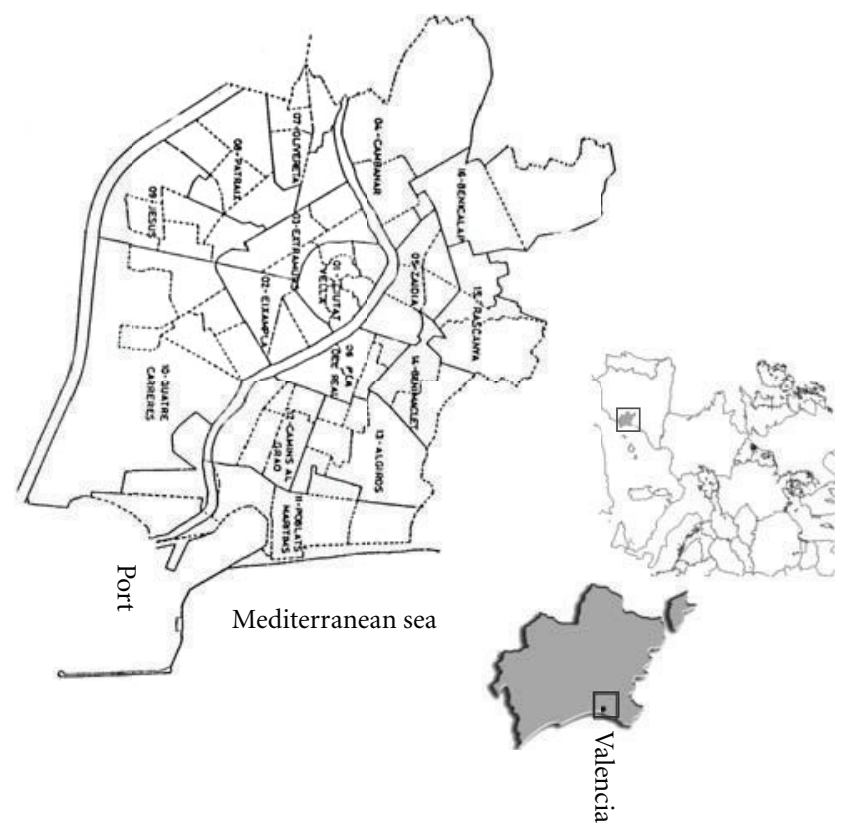

FIGURE 1: Map of Valencia with the neighbourhoods included in the sample.

Politécnica in Valencia (professors, research staff, administration, and services staff). The architects were considered to be "experts" in urban design as in Spain they have the necessary academic qualifications to become town planners. The architects in the sample came from departments related to architecture or town planning. The sample size was chosen with the criterion of having 8 cases per adjective. This sample size is greater than the number of 300 indicated as sufficient in field [33]. Each subject replied to 3 questionnaires to give a total of 420 replies.

The questionnaire contained 59 adjectives to describe citizens' emotional response when evaluating areas of a city. Only words and expressions in Spanish were collected. This set of adjectives was obtained through a word search (142 adjectives) on neighbourhood evaluation. Most of the expressions were found on the Internet, in newspapers, journals, and professional magazines. This set of words was reduced using the affinity diagram which groups semantic descriptions according to their affinity [34]. In addition to these expressions, two variables were included in the questionnaire which reflected the overall evaluation of the area. Thus, residential choice was obtained by the expression "Assuming I found a flat in this neighbourhood which suited my needs and possibilities, I would like to live there". Investment choice was introduced with the expression "I think it is a good area to invest in, assuming I found a flat in the area which adapted to my needs and possibilities, I would invest there". A 5-point Likert scale was used for evaluating each image ranging from: totally disagree, disagree, neutral, agree, and totally agree.

2.2. Stimuli. The set of stimuli used to develop the field study consisted of a total of 74 images of the different neighbourhoods in the city of Valencia. Each stimulus had a graphically defined set of streets for evaluation. In addition to facilitating recognition of the area, it was given the name used by the City Council and its popular commercial name. Figure 2 shows an example of the stimuli used.

2.3. Development of the Field Study. The interviewees were informed of the objectives of the study, and we asked them to fill in questionnaires expressing their opinions in a spontaneous way. It was therefore considered necessary for interviewees to know the neighbourhood being evaluated, and if they did not, they were asked about a different area. The order of questions was randomized for each individual questionnaire in order to avoid bias.

\subsection{Data Processing.}

(1) Verification of Significant Differences between Architects and Nonarchitects Considering the Initial Set of Adjectives. In a first phase, discriminant analysis was used to evaluate the differences in perception of the set of variables using the variable which represents the collectives of architects and nonarchitects as a grouping variable and the scores for the different adjectives as independent variables. It was thereby possible to verify the hypothesis that architects and nonarchitects have a sufficiently different perception structure to be able to classify a person by their responses. The indicators used to evaluate the efficiency of the discriminant function were: the eigenvalue of the discriminant function, the canonical correlation, and the Wilks' Lambda value.

(2) Verification of Significant Differences between Architects and Nonarchitects Considering the Variables "Residential Choice" and "Investment Choice". First of all the distribution of both variables was analysed. Then an ANOVA was applied to evaluate the differences in perception in the variables which reflect the choice of the area.

(3) Reducing the Set of Perception Variables. We use differential semantics developed by Osgood et al. [35]. The technique analyses the correlation matrixes for the scores for terms over a set of products. If it can be demonstrated that a limited number of dimensions or factors is sufficient to differentiate between the meanings of the whole set of concepts, then these dimensions define a semantic basis for expressing any product. This semantic basis is known as semantic space, and each concept is a semantic axis. This technique is one of the most commonly used methods for assessing product perception in Kansei Engineering studies [36-38]. The statistical technique used to identify and extract the semantic axes was principle components factor analysis [39, 40]. We selected only principal components with eigenvalues greater than one, and a further Varimax rotation was made to obtain the semantic axes factors. Finally, internal consistency of the dimensions was evaluated by Cronbach's Alpha coefficient [41].

(4) Ranking Semantic Axes According to Importance in "Residential Choice" and "Investment Choice". Then, the ranking of axes or perceptions which influence the choice of a certain 


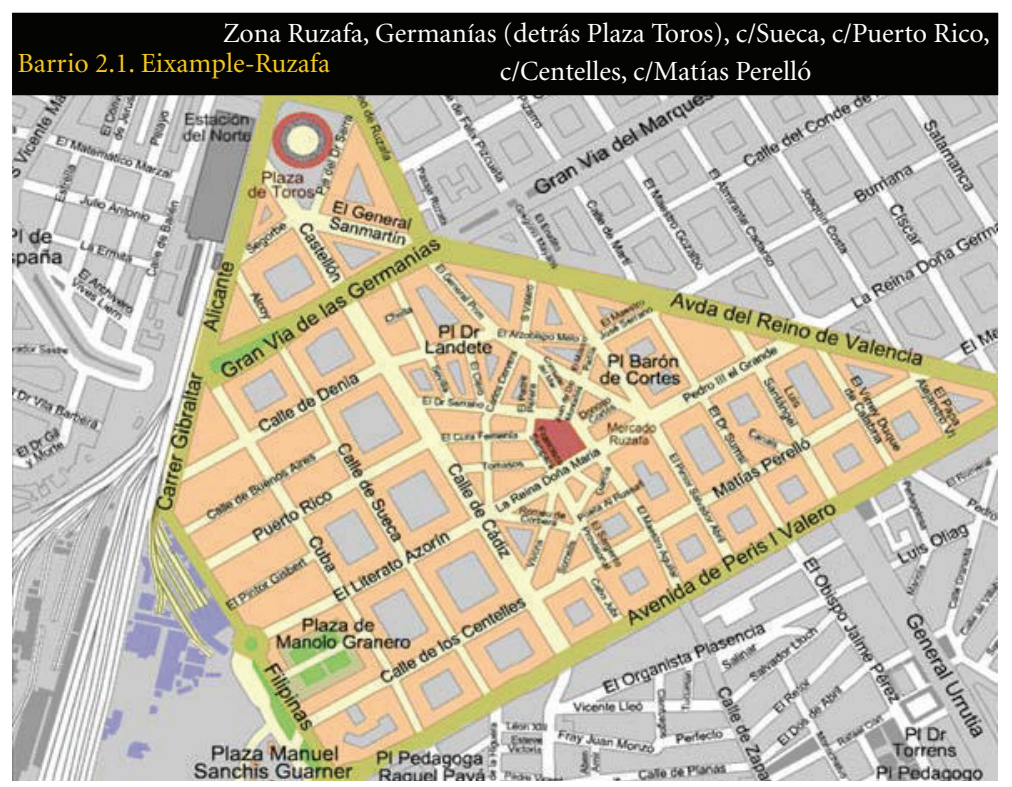

Figure 2: Example of the stimuli used in the field study.

residential environment for each collective was determined by applying regression analysis to the choice of neighbourhood (residential or investment) as the predictive variable.

(5) Comparative Analysis. Semantic Profile. The semantic profile of a specific neighbourhood is a diagram that represents the scores obtained on each semantic axis and the overall evaluation (residential or investment choice). This graph allows us to visualise the relative position of a particular neighbourhood with respect to the mean of the other areas in the city. Thus we can represent the perception that architects and non architects have of a given neighbourhood and compare their impressions. This was done by analysing one particular neighbourhood based on a sample of 15 additional questionnaires not included in the above statistical analysis.

Statistical analyses were carried out using statistical package SPSS.16.0.

\section{Results}

3.1. Verification of Significant Differences between Architects and Nonarchitects Considering the Initial Set of Adjectives. Discriminant analysis was used to determine the existence of significant differences between both collectives based on the set of adjectives analysed. This test determined a single discriminant function. The discriminating power of this function was moderate, with a canonical variation of 0.358 and an eigenvalue of 0.147 . The separation given by the discriminant function was significant, with a Wilks' Lambda value of 0.872 (see Table 1). The results therefore suggest that there are significant differences between architects and nonarchitects' perceptions of the set of adjectives analysed.

3.2. Verification of Significant Differences between Architects and Nonarchitects Considering the Variables "Residential Choice" and "Investment Choice". For the "residential
TABle 1: Eigenvalue, canonical correlation, Wilks Lambda, and signification level of the discriminant function.

\begin{tabular}{ll}
\hline Eigenvalue & .147 \\
Canonical correlation & .358 \\
Wilks' Lambda & .872 \\
Signification level & .000 \\
\hline
\end{tabular}

choice" variable, descriptive analysis shows a tendency for both collectives to evaluate the same areas positively. $57 \%$ of architects and $53 \%$ of nonarchitects valued positively the same areas of the city for residential purposes (Figure 3). Since the sample of stimuli is the same, when a group replies with lower central values that suggests a higher level of demand. Thus, the collective of nonarchitects appears more demanding than the architects on this variable.

Furthermore, the ANOVA shows no significant differences between both collectives in residential choice decision (for a significance level of 0.05) (Table 2).

3.3. Questionnaire. For the "investment choice" variable, again descriptive analysis shows a tendency for both groups to evaluate the same areas positively. $59 \%$ of architects and $51 \%$ of nonarchitects valued positively the same areas of the city for investment (Figure 4). Again the collective of nonarchitects appears more demanding than the architects as the central value is lower.

In this case, the ANOVA (Table 3) shows that the differences in this decision are not significant either although it is close to the 0.05 level of significance.

In short, although there are no significant differences it appears that there are more differences when the final choice is investment rather than residential. In any case, it seems appropriate to analyse what each evaluation depends on. 


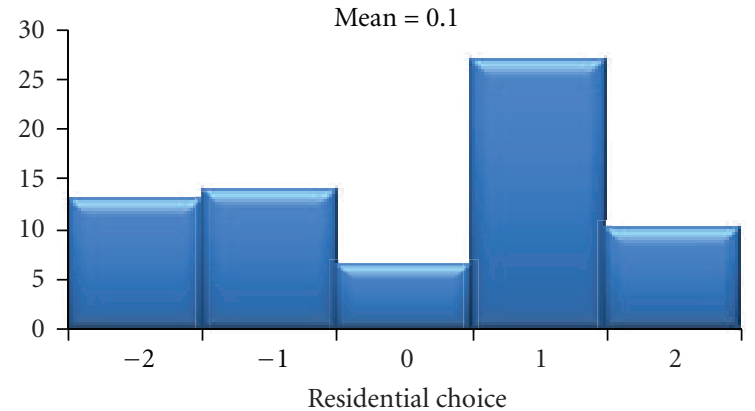

(a)

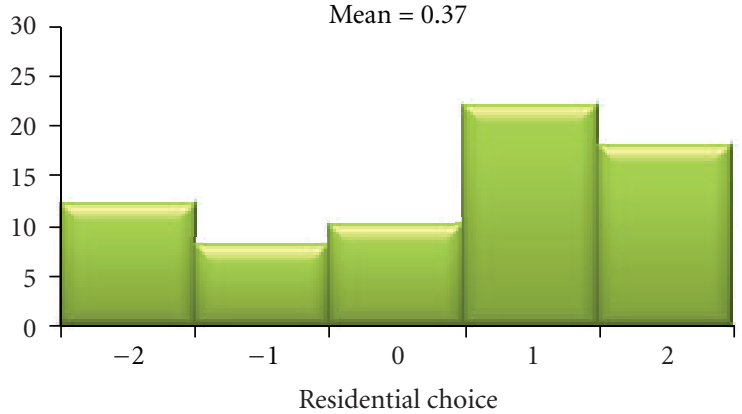

(b)

FIgURE 3: Evaluation of the variable "residential choice": (a) nonarchitects (b) architects.

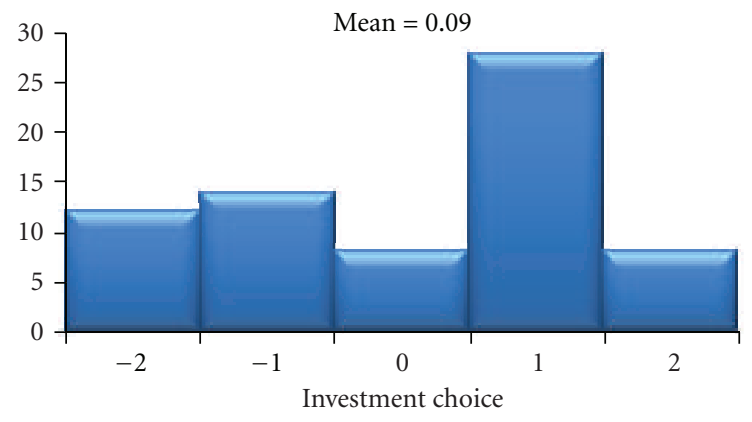

(a)

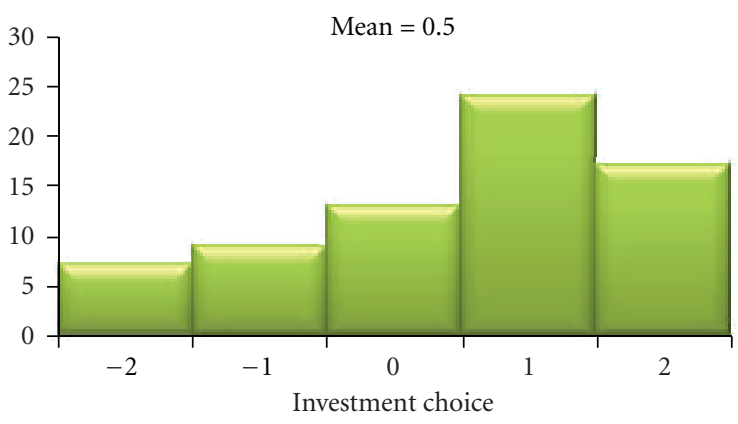

(b)

FIgURE 4: Evaluation of the variable "investment choice": (a) nonarchitects (b) architects.

TABle 2: Residential choice ANOVA.

\begin{tabular}{lccccc}
\hline Source & SS & df & MS & F & Sig \\
\hline Residential choice & & & & & \\
Intergroups & 2.579 & 1 & 2.579 & 1.305 & .255 \\
Intragroups & 272.643 & 138 & 1.976 & & \\
Total & 275.221 & 139 & & & \\
\hline
\end{tabular}

TABLE 3: Investment choice ANOVA.

\begin{tabular}{lccccc}
\hline Source & SS & df & MS & F & Sig \\
\hline Investment choice & & & & & \\
Intergroups & 6.007 & 1 & 6.007 & 3.558 & .061 \\
Intragroups & 232.986 & 138 & 1.688 & & \\
Total & 238.993 & 139 & & & \\
\hline
\end{tabular}

3.4. Reducing the Set of Perception Variables. Factor analysis later reduced the 59 expressions on assessment of the areas to 14 uncorrelated factors which explained $71.4 \%$ of the variance. Table 4 shows the selected factors, their correlations with the original adjectives, and the percentage of explained variance.

Axis 1 represents the with charm, emblematic, and unique axis with flavour, charm, emblematic, unique, tourist area, and in surroundings of cultural interest as main concepts. Axis 2 comprises the adjectives luxury, prestige, noble, expensive flats, and elegant. It is related to the concept of luxury and prestige. Axis 3 determines wide and landscaped with wide, big open spaces, and landscaped and leisure areas, with wide avenues and the negative decaying, deteriorated. Axis 4 refers to the character of the area being developed, not consolidated. Concepts such as expanding, urban development, with promising future prospects, and the negative established and consolidated are very significant in this axis. Axis 5 represents the dimension well located with the adjectives well-located, good public transport links, with wide, easy, fast access routes, and easy to reach the workplace. Axis 6 contains pleasant, agreeable, with quality of life concepts and the negative multicultural, contrasts, and with immigrants. It is the nonmulticultural axis. Axis 7 can be understood as commercial and business area with the adjectives commercial, with good shops and business area. Axis 8 with the expressions friendly and welcoming, peaceful, pleasant, and agreeable, and the negative noisy represents the dimension of peaceful and friendly. Axis 9 represents the dimension youthful nature and leisure with the main adjectives being youthful, vital, cheerful, with leisure and entertainment services, plenty of nightlife and carefree and lively, dynamic. Axis 10 represents urban and with good facilities axis as it contains the adjectives urban character and with good facilities, infrastructures and services. Axis 11 contains the concept with no safety problems as the only expression. Axis 12 refers to ongoing construction work as it only contains this concept. Axis 13 is the with a wide choice of schools axis, as it only contains this descriptive. Finally, axis 14 is with traffic 
TABle 4: Factor analysis.

\begin{tabular}{|c|c|c|c|c|c|c|c|c|c|c|c|c|c|c|}
\hline \multirow[t]{2}{*}{ Item } & \multicolumn{14}{|c|}{ Factor } \\
\hline & 1 & 2 & 3 & 4 & 5 & 6 & 7 & 8 & 9 & 10 & 11 & 12 & 13 & 14 \\
\hline$\%$ Variance explained & 25.3 & 10.7 & 5.9 & 4.7 & 4.2 & 3.1 & 2.7 & 2.7 & 2.5 & 2.1 & 2.0 & 1.9 & 1.8 & 1.8 \\
\hline Cronbach's alpha & .92 & .93 & .74 & .74 & .59 & .75 & .69 & .64 & .76 & .39 & 一 & 一 & .21 & .01 \\
\hline With flavour, charm & .84 & & & & & & & & & & & & & \\
\hline Emblematic & .82 & & & & & & & & & & & & & \\
\hline Unique, special, unrepeatable & .81 & & & & & & & & & & & & & \\
\hline Tourist area & .78 & & & & & & & & & & & & & \\
\hline In surroundings of cultural interest & .78 & & & & & & & & & & & & & \\
\hline With personality and own character & .68 & & & & & & & & & & & & & \\
\hline In historical surroundings & .66 & & & & & & & & & & & & & \\
\hline With good views & .62 & & & & & & & & & & & & & \\
\hline Traditional, long-established & .60 & & & & & & & & & & & & & \\
\hline Well situated & .60 & & & & & & & & & & & & & \\
\hline Fashionable & .48 & & & & & & & & & & & & & \\
\hline Good investment with revaluation possibilities & .46 & & & & & & & & & & & & & \\
\hline Avant-garde & .44 & & & & & & & & & & & & & \\
\hline Luxury & & .79 & & & & & & & & & & & & \\
\hline Prestige & .46 & .75 & & & & & & & & & & & & \\
\hline Noble & & .71 & & & & & & & & & & & & \\
\hline With expensive flats & & .69 & & & & & & & & & & & & \\
\hline Elegant & .55 & .59 & & & & & & & & & & & & \\
\hline Marginal & & .41 & & & & & & & & & & & & \\
\hline Wide, big open spaces & & & .75 & & & & & & & & & & & \\
\hline With parks and leisure areas & & & .69 & & & & & & & & & & & \\
\hline Decaying, deteriorated & & & -.57 & & & & & & & & & & & \\
\hline With wide avenues & & & .54 & & & & & & & & & & & \\
\hline Feeling of community & & & -.45 & & & & & & & & & & & \\
\hline Expanding, urban development & & & & .79 & & & & & & & & & & \\
\hline Established and consolidated & & & & -.59 & & & & & & & & & & \\
\hline In a natural, countryside environment & & & & .59 & & & & & & & & & .43 & \\
\hline With promising future prospects & & & & .56 & & & & & & & & & & \\
\hline Easy to park & & & & .53 & & & & & & & & & & \\
\hline Contemporary, modern & & & & .48 & & & & & & & & & & \\
\hline Well located & & & & & .84 & & & & & & & & & \\
\hline Good public transport links & & & & & .72 & & & & & & & & & \\
\hline With wide, easy, fast access routes & & & & & .62 & & & & & & & & & \\
\hline Easy to reach the workplace & & & & & .61 & & & & & -.43 & & & & \\
\hline Multicultural & & & & & & -.74 & & & & & & & & \\
\hline Contrasts & & & & & & -.64 & & & & & & & & \\
\hline Pleasant, agreeable & .40 & & & & & .50 & & .47 & & & & & & \\
\hline With immigrant & & &,- 42 & & & -.46 & & & & & & & & \\
\hline Quality of life & & & & & & .45 & & & & & & & & \\
\hline Good urban planning & & & & & & .44 & & & & & & & & \\
\hline Commercial & & & & & & & .77 & & & & & & & \\
\hline With good shops & & & & & & & .72 & & & & & & & \\
\hline Business area & & & & & & & .61 & & & & & & & \\
\hline Noisy & & & & & & & & -.75 & & & & & & \\
\hline Friendly and welcoming & & & & & & & & .66 & & & & & & \\
\hline Peaceful & & & & & & & & .56 & & & & & & \\
\hline Youthful, vital, cheerful & & & & & & & & & .66 & & & & & \\
\hline With leisure and entertainment services & .44 & & & & & & & & .54 & & & & & \\
\hline
\end{tabular}


Table 4: Continued.

\begin{tabular}{|c|c|c|c|c|c|c|c|c|c|c|c|c|c|c|}
\hline \multirow[t]{2}{*}{ Item } & \multicolumn{14}{|c|}{ Factor } \\
\hline & 1 & 2 & 3 & 4 & 5 & 6 & 7 & 8 & 9 & 10 & 11 & 12 & 13 & 14 \\
\hline \% Variance explained & 25.3 & 10.7 & 5.9 & 4.7 & 4.2 & 3.1 & 2.7 & 2.7 & 2.5 & 2.1 & 2.0 & 1.9 & 1.8 & 1.8 \\
\hline Cronbach's alpha & .92 & .93 & .74 & .74 & .59 & .75 & .69 & .64 & .76 & .39 & - & - & .21 & .01 \\
\hline Plenty of nightlife and carefree & .42 & & & & & & & & .52 & & & & & \\
\hline Lively, dynamic & & & & & & & .40 & & .49 & & & & & \\
\hline Pedestrian areas & & & .41 & & & & & & .47 & & & & & \\
\hline Good sports facilities & & & & & & & & & .45 & & & & & \\
\hline Urban character & & & & & & & & & & .67 & & & & \\
\hline With good facilities, infrastructures, and services & & & & & & & & & & .56 & & & & \\
\hline With no safety problems & & & & & & & & & & & .80 & & & \\
\hline Ongoing construction work & & & & & & & & & & & & .77 & & \\
\hline With a wide choice of schools & & & & & & & & & & & & & .75 & \\
\hline Heavy traffic & & & & & & & & -.43 & & & & & & .56 \\
\hline Influenced by the sea & & & & .46 & & & & & & & & & & -.47 \\
\hline
\end{tabular}

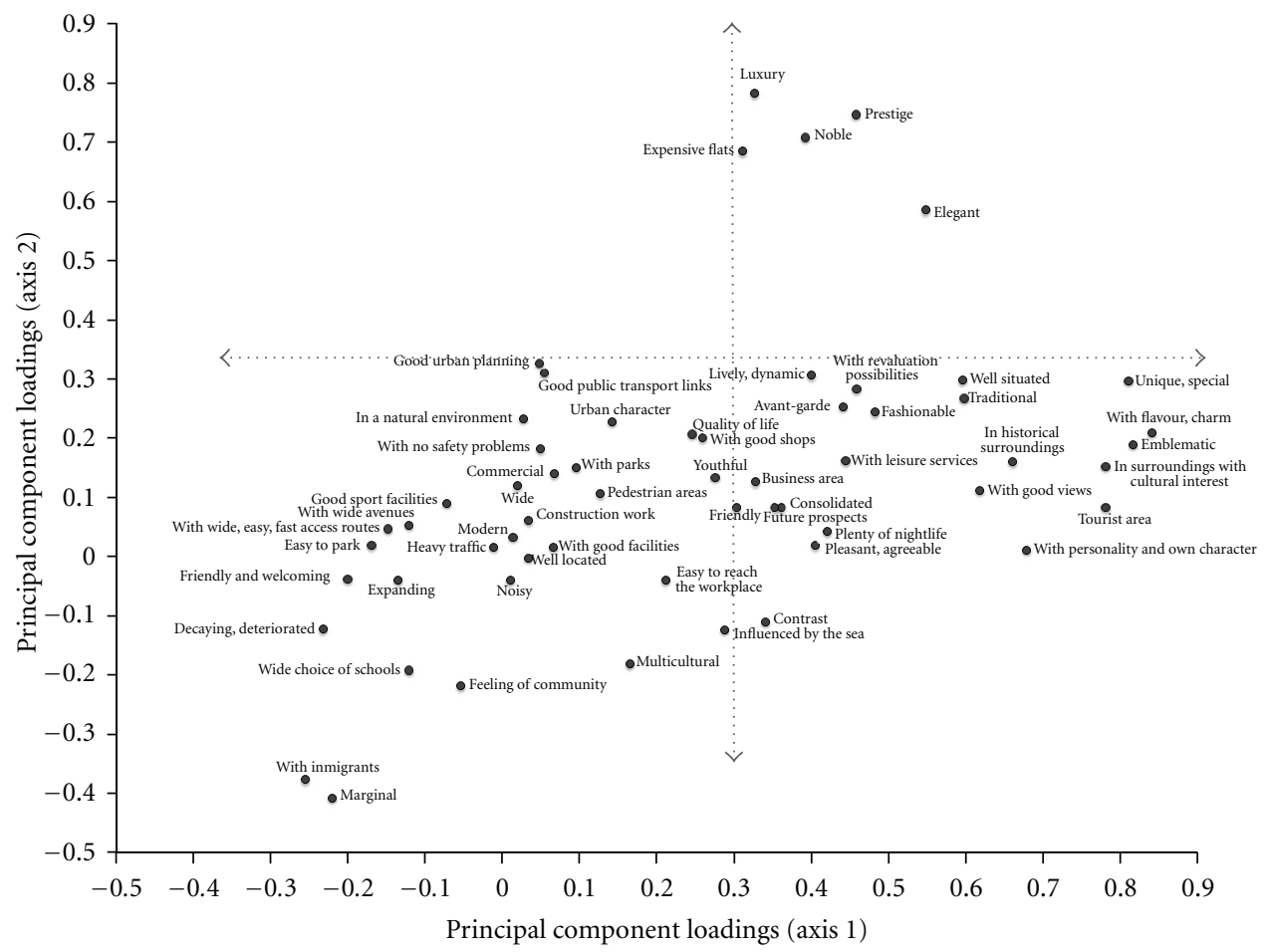

FIGURE 5: Plot of principal component loadings.

axis. It contains the expressions with heavy traffic and influenced by the sea.

Figure 5 shows the first and second principal component loadings. The first axis contrasts flavour, emblematic, touristic, cultural, historical, and natural, with good sport facilities and wide avenues. The second axis contrasts the concepts of luxury, prestige, noble, expensive flats, elegant with multicultural, feeling of community, and marginal and inmigrants.

Then, Cronbach's Alpha values were calculated for all the dimensions. Following Streiner's [41] criteria, factors with a very low alpha (axes 10,11,12, 13, and 14) were eliminated because it was considered that these scales were not very reliable.

3.5. Ranking Semantic Axes According to Importance in the "Residential Choice" and "Investment Choice". For the "residential choice" variable the model determined a total of 4 significant factors for both collectives $(P<0.05)$ (Table 5).

The model for the architects has a correlation coefficient of 0.748 . The factor with the greatest influence in the residential area decision is the one which reflects the perception of area with charm, emblematic, and unique a correlation of 
TABLE 5: Factor ordering according to influence on residential choice (regression analysis).

\begin{tabular}{lccccc}
\hline & $B$ & SE & Beta & $t$ & Sig. \\
Nonarchitects & & & & & \\
\hline (Constant) & .163 & .125 & & 1.308 & .196 \\
Luxury and prestige & .485 & .135 & .352 & 3.598 & .001 \\
Peaceful and friendly & .474 & .153 & .303 & 3.095 & .003 \\
With charm, emblematic & .453 & .128 & .325 & 3.535 & .001 \\
Not multicultural, no immigrants .370 & .124 & .282 & 2.986 & .004 \\
& & & & $R=.721$ & \\
\hline Architects & & & & & \\
\hline Constant) & .334 & .126 & & 2.657 & .010 \\
With charm, emblematic & .803 & .130 & .573 & 6.155 & .000 \\
Luxury and prestige & .459 & .137 & .329 & 3.351 & .001 \\
Peaceful and friendly & .387 & .117 & .308 & 3.292 & .002 \\
Not multicultural, no immigrants .362 & .146 & .243 & 2.481 & .016 \\
& & & & $R=.748$ & \\
\hline
\end{tabular}

over 0.80 . Then, with a correlation of over 0.4 is the variable which reflects perception of luxury and prestige. Finally, with correlations in the interval $0.35-0.40$ are the impressions of a peaceful, friendly area and not multicultural area. Although the model for the collective of nonarchitects with a correlation coefficient of 0.721 includes the same factors, the order is different. Thus, perceptions of luxury, prestige, peaceful and friendly, and with charm and emblematic correlate positively in the interval $0.45-0.50$. As in the case of the architects, the impression that the area is not multicultural also influences the residential decision, but less significantly (with a correlation of 0.37 ).

Models were obtained for the "investment choice" variable in a similar fashion (Table 6).

For the collective of architects the model includes 6 significant factors. The correlation coefficient is 0.756 . The most significant axes in this variable reflect the perceptions of the area with charm, emblematic, luxury, and prestige with positive correlations in the interval $0.65-0.70$. This is followed by well-located area with a correlation of 0.37 . Finally, with correlations in the interval $0.25-0.30$ perceptions of peaceful, youthful, wide, and landscaped For nonarchitects the model reflects 5 relevant factors. The correlation coefficient is 0.718 . Outstanding, with a correlation of over 0.50 , is the factor which reflects the perception of the area as being with charm and emblematic. Then correlations between $0.30-0.40$ are the perceptions of the area as luxury, not multicultural and peaceful. This is followed by the factor of wide and landscaped area with a correlation of 0.25 .

3.6. Comparative Analysis. Semantic Profiles. Finally and in order to represent the differences in perception between both collectives one of the areas in the city was chosen for semantic profiling. Figure 6 shows the stimuli for one particular neighbourhood.

To give the reader a better idea, we have included photographs of the area (Figure 7). These photos were not used as stimuli as the idea was to analyse the impression of the neighbourhood.
TABLE 6: Factor ordering according to influence on investment choice (regression analysis).

\begin{tabular}{lccccc}
\hline & $B$ & SE & Beta & $t$ & Sig. \\
Nonarchitects & & & & & \\
\hline (Constant) & .155 & .120 & & 1.291 & .202 \\
With charm, emblematic & .533 & .123 & .400 & 4.326 & .000 \\
Luxury and prestige & .358 & .130 & .271 & 2.765 & .008 \\
Not multicultural, no immigrants .355 & .119 & .283 & 2.976 & .004 \\
Peaceful and friendly & .334 & .147 & .223 & 2.270 & .027 \\
Wide and landscaped & .255 & .127 & .196 & 2.003 & .050 \\
& & & & $R=.718$ & \\
\hline Architects & & & & & \\
\hline Constant) & .395 & .112 & & 3.537 & .001 \\
With charm, emblematic & .679 & .116 & .537 & 5.850 & .000 \\
Luxury and prestige & .652 & .122 & .519 & 5.353 & .000 \\
Well located & .373 & .123 & .268 & 3.032 & .004 \\
Peaceful and friendly & .271 & .105 & .239 & 2.587 & .012 \\
Youthful nature and leisure & .267 & .117 & .214 & 2.290 & .026 \\
Wide and landscaped & .261 & .119 & .203 & 2.181 & .033 \\
& & & & $R=.756$ & \\
\hline
\end{tabular}

Figure 8 shows the semantic profile of the area for architects and nonarchitects. Axes are ordered from greatest to least difference between both collectives for ease of interpretation. Thus the greatest differences in evaluation occur in the axis which reflects well-located area and the least in the commercial and business character.

It can be seen that the overall evaluations of both collectives are quite different. Whereas architects would choose this area for residence and investment, the other group would not. What is the reason for these differences? Account must be taken of the fact that for architects the most significant variable in the residential choice decision is an emblematic appearance, with charm and unique and this factor is very highly valued. It seems that this very positive evaluation compensates for the fact that it is not perceived as luxury, prestige, peaceful, or friendly (significant variables in the model). Nonarchitects also perceive the area as with charm and emblematic but this factor does not manage to compensate (it is not so significant in the model) for the negative evaluations in the perceptions of peaceful, friendly and not multicultural area.

With regard to investment choice, the architects' decision is very positive. It appears that the sensation that it is an area with charm, emblematic, well-located, good public transport links, youthful, and with leisure and entertainment services compensates for the fact that it is not considered to be luxury, peaceful, wide or landscaped. For nonarchitects however, as the residential and investment models are practically similar the final decision is also negative. For this collective, the area does not give a sensation of luxury, it is multicultural and not very wide or landscaped. These evaluations do not seem to compensate for the fact that it is perceived as having charm or being emblematic. Thus, the final evaluation for this collective is again negative. 


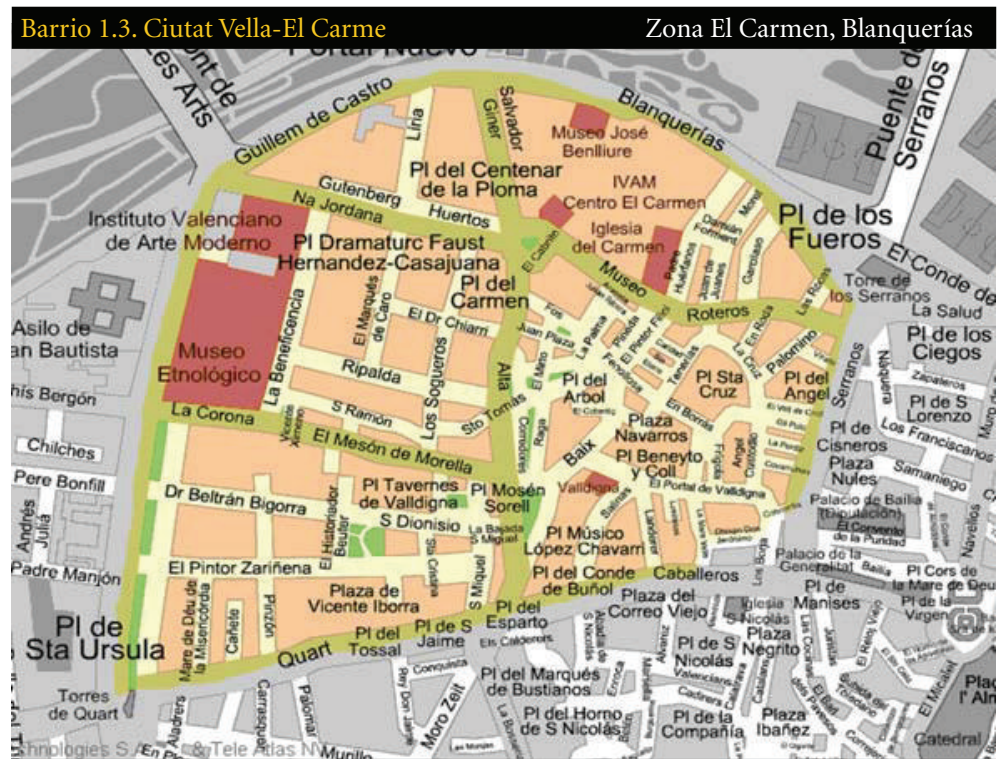

Figure 6: Stimuli of the particular neighbourhood evaluated.
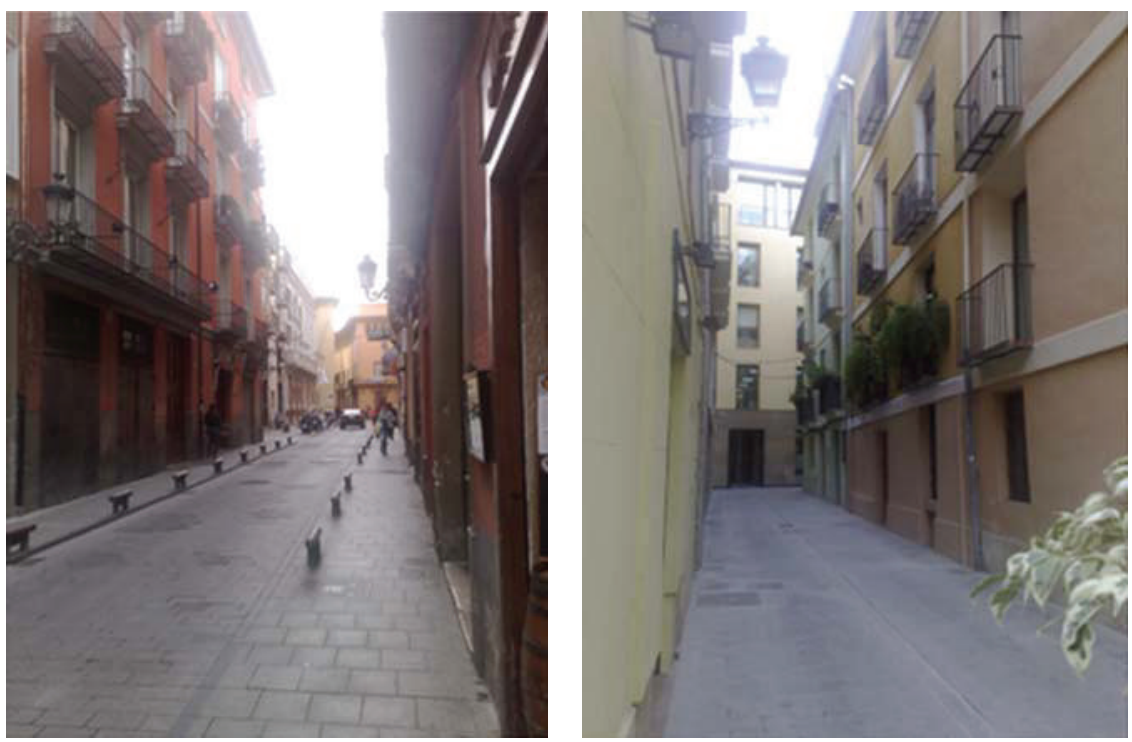

FIGURE 7: Real images of the particular neighbourhood evaluated.

\section{Discussions and Conclusions}

In this paper we have analysed the differences between architects and nonarchitects in their emotional assessments of different districts in their own city for the purposes of choosing a given residential or investment area.

This study provides significant implications on three levels: it contributes to the theory, methodology, and application.

At the theoretical level, it can be concluded that both collectives' (architects and nonarchitects) evaluation scheme shows no significant differences in the decision to choose an area in the city. Thus, while there appear to be important differences in the initial set of adjectives, this does not hold for the choice of area variables (residential or investment). That is, the emotional attributes which determine the choice of area are very similar for architects and nonarchitects. Greater discrepancies, however, were found when the purpose of the choice was investment and not residential. Although there are no similar studies with which to compare these results, it is worth emphasising the difference in this conclusion with the studies to date which report significant differences between architects and nonarchitects when evaluating buildings $[2,6,7,11,12]$.

From the methodological point of view the most outstanding contribution is the application of Kansei methodology to evaluate urban areas of a city to detect different evaluations made by the group of architects and nonarchitects. In 


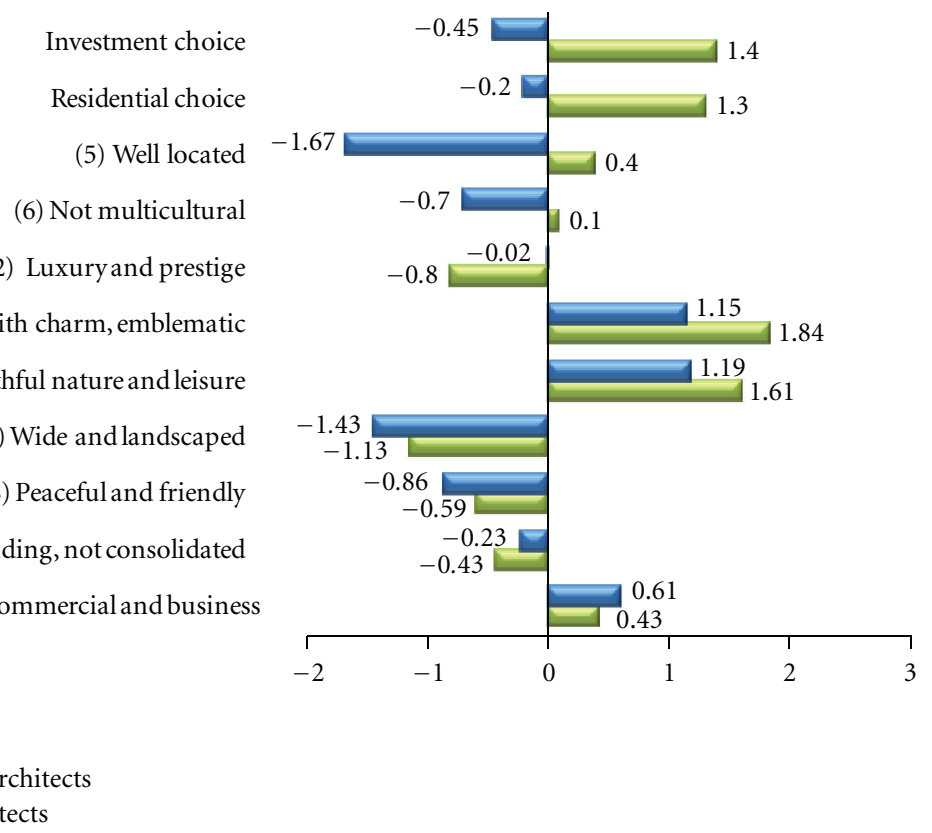

FIGURE 8: Comparison of semantic profiles of the neighbourhood evaluated (nonarchitects-architects).

particular, the first phase of this methodology has been developed using differential semantics as a verbal measurement instrument by measuring the subjective component of the emotional state which both collectives are able to recognise. Differential semantics has been previously applied in the field of residential environments with the aim of determining general perceptual qualities that people use to characterize architecture and the built environment [31,32]. Our approach presents some differences with these earlier papers because we use differential semantics as a first step within the context of Kansei engineering. Other similar applications in the field of architecture can be found in the design of facades [42], doors [37], perception of properties on sale [38], and the most recent applied to urban design [43]. This study, however, is the first time an application of the technique has been proposed to detect differences in the emotional evaluation between two collectives.

With respect to the contribution to application, the findings of this study provide three important outcomes.

Firstly, a 9-dimension model for perception of the analysed urban area with a $61.8 \%$ capacity is to reproduce perception variability in the sample. The semantic axes represent concepts related to the neighbourhood's appearance (1st axis, with charm, emblematic; 2 nd axis, luxury and prestige and 6th axis, not multicultural), good urban planning (3rd axis, wide and landscaped), character or area in expansion or not consolidated (4th axis), good services (5th axis, welllocated, with easy access and 7th axis, commercial and business) and pace of life (9th and 8th axes, youthful character, leisure, and peaceful, resp.). These axes provide a tool for objective measurement of the perceptions that different areas in the city of Valencia arouse in users (architects and nonarchitects). A similar study was done in 2004 [43]. The semantic field extracted on that occasion, with a similar sample and stimuli, was very similar to that obtained in this present study. Although practically all the concepts coincide, the inclusion of a new factor should be noted, the nonmulticultural area perception. Over recent years there has been a progressive increase in the number of immigrants in Spain. In particular, the immigrant population in the city of Valencia has tripled over the last five years.

Secondly, the significance of each semantic concept in the final evaluation of areas in the city has been analysed to provide descriptive maps of the emotional evaluation associated to the stimulus for both collectives. In the residential choice decision, it can be stated that for architects and nonarchitects perception of an urban area as emblematic, unique, luxury and prestige, peaceful and welcoming, and not multicultural will maximise the success. However, these perceptions are ordered differently in the two groups. For architects areas with charm and emblematics are very important. For nonarchitects however, the appearance of luxury and prestige and the sensation of a peaceful, friendly area are more important. The differences are more significant when the area is being chosen for investment purposes. For both collectives it is important that the area gives the impression of being emblematic, unique, and luxury. As in the above case the factor of being an area without noise, friendly, welcoming, and peaceful is also important. However, for investment purposes, architects focus on aspects related to services in the area; thus it is with easy access and is perceived of as youthful and for leisure while nonarchitects also take into account the fact that it is not perceived of as multicultural. In both cases the last significant factor in the decision to invest is that the area is perceived of as wide and landscaped. It should be noted with regard to the multicultural factor that the immigrant population has tended to concentrate in the most disadvantaged areas of the city with lack of green spaces, 


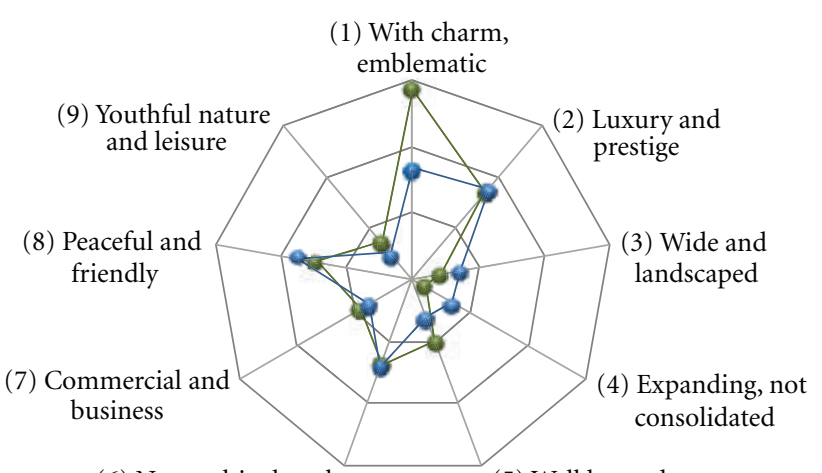

(6) Not multicultural

(5) Well located

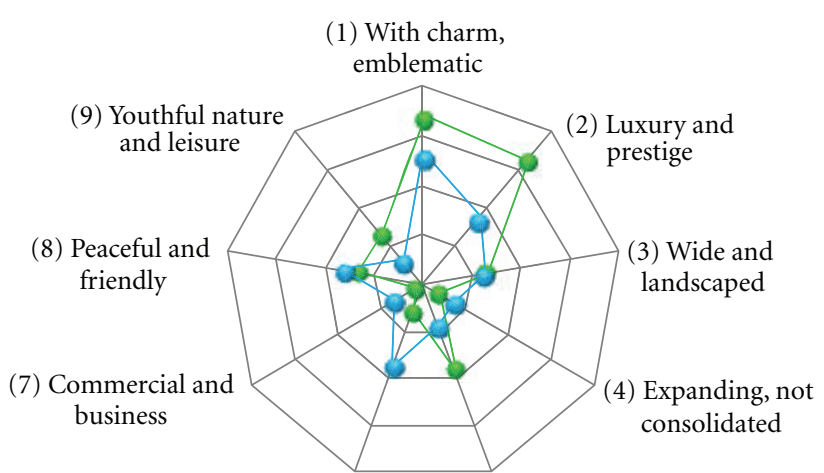

(6) Not multicultural

(5) Well located
- Architects
- Nonarchitects

(a)

\section{- Architects \\ - Nonarchitects}

FIGURE 9: Radial representation of absolute values for beta coefficient of the linear regression between the semantic axes and the choice of neighbourhood: (a) residence (b) investment.

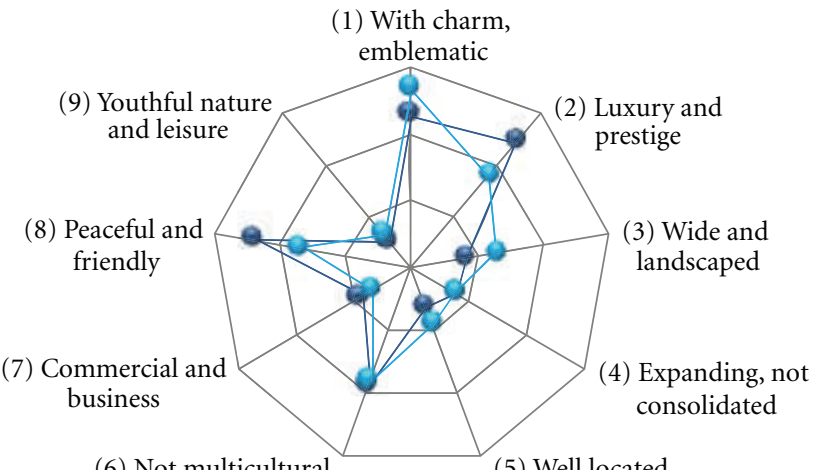

(6) Not multicultural
(5) Well located

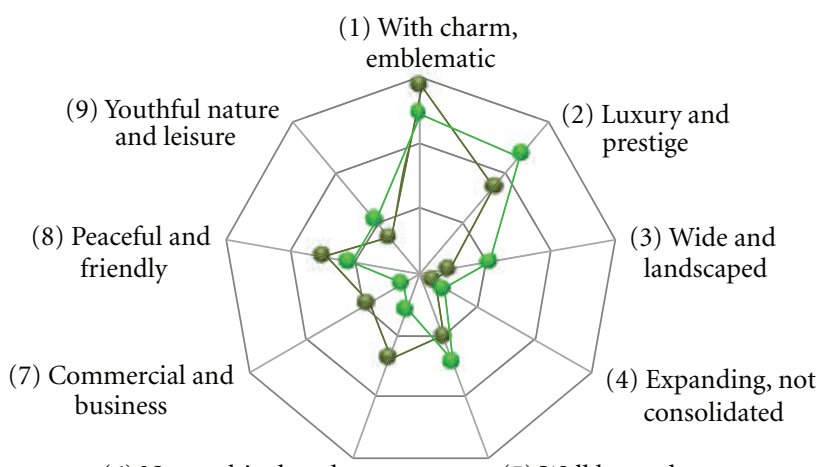

(6) Not multicultural
Residence

Investment

(a)

FIGURE 10: Radial representation of absolute values for beta coefficient of the linear regression between the semantic axes and the choice of neighbourhood: (a) nonarchitects (b) architects.

excessive noise levels, lack of cleanliness, and high levels of delinquency and vandalism. Perhaps that is why the individuals in the sample gave a negative evaluation to multiculturality in the residential decision (Figure 9).

It is interesting to see the differences in the same collective in relation to the duality in the residential or investment choice (Figure 10). For architects the area's appearance influences both decisions; it must give the impression of being an area with charm, emblematic, luxury, prestige, and be perceived of as peaceful and welcoming, although this last factor is more significant in the residential decision. The greatest differences for architects are found in multiculturality, an important aspect in the residential choice but not the investment choice which is a decision based on other aspects such as the area's services, that it is well-located or with easy access, with leisure and entertainment services, and big open spaces, parks, and leisure areas. For nonarchitects there are not so many differences in the aspects influencing both decisions. The appearance of the area, with charm, luxury, not multicultural and that it is perceived of as peaceful and welcoming are significant in both decisions. There is only one final significant factor but with a very low weight in the investment decision, that the area is wide and landscaped.

Thirdly, the semantic profiles of both collectives have been obtained with regard to a specific area of the city. These semantic profiles may be very useful to town planners when planning a city as they provide insights to analyse the perception of specific neighbourhoods.

The results of this study are not comparable with previous studies as most have focused on analysing what aspects of the urban environment manage to improve or worsen the overall appearance. Thus, spacious well-structured setting 
[44] and the presence of natural elements [45] seem to engender the highest preferences, and traffic can diminish the overall appearance of the street $[46,47]$. These results are not comparable because although certain factors improve or worsen the visual appearance of the urban environment, they are not necessarily relevant when choosing where to live or invest. Furthermore, low scores in certain factors can be compensated by other more important factors.

In terms of future lines of work, after obtaining architects and nonarchitects' affective dimensions which influence the choice of area, it could be interesting to identify what design elements in the urban environment cause them. For example, it has been seen that both groups coincide in the importance of an area being perceived as having charm and being emblematic, but what does each collective focus on specifically to arrive at this evaluation? what design elements in the urban environment cause it? This relation between design elements and semantic attributes constitutes the second phase in Kansei methodology and can be determined by applying statistical treatments such as linear regression [37, 48], neural networks [49], or fuzzy logic [50].

Finally, the limitations to be taken into account are firstly that the results obtained cannot be extrapolated for cities other than Valencia. When evaluating a specific city, the obtained axes are specific to this city in particular, with its singular characteristics as perceived by the inhabitants. Secondly, the sample used is representative of a given market segment. This limitation is given by the need to use homogeneous population groups. Account should be taken of the fact that the inclusion of different groups can cause high intergroup variability which can alter the structure of the semantic axis.

\section{References}

[1] H. Gans, "Towards a human architecture: a sociologist view of the profession," Journal of Architectural Education, vol. 2, pp. 26-31, 1978.

[2] L. N. Groat, "Meaning in post-modern architecture: an examination using the multiple sorting task," Journal of Environmental Psychology, vol. 2, no. 1, pp. 3-22, 1982.

[3] C. Friedman, J. D. Balling, and J. J. Valadez, "Visual preference for office buildings: a comparison of architects and non-architects," in Proceedings of the Annual Conference of the Environmental Design Research Association, 1985.

[4] M. Duffy, S. Bailey, B. Beck, and D. G. Barker, "Preferences in nursing home design: a comparison of residents, administrators and designers," Environment and Behavior, vol. 18, pp. 246-257, 1986.

[5] J. C. Vischer and C. C. Marcus, "Evaluating evaluation: analysis of a housing design awards program," Places, vol. 3, pp. 66-86, 1986.

[6] K. Devlin and J. Nasar, "The beauty and the beast: some preliminary comparisons of "high" versus "popular" residential architecture and public versus architect judgments of same," Journal of Environmental Psychology, vol. 9, no. 4, pp. 333-344, 1989.

[7] K. Devlin, "An examination of architectural interpretation: architects versus nonarchitects," in Design Review: Challenging Urban Aesthetic Control, B. C. Scheer and W. F. E. Preiser, Eds., pp. 156-164, Chapman \& Hall, New York, NY, USA, 1990.
[8] J. L. Nasar and T. Purcell, "Beauty and the beast extended: knowledge structure and evaluations of houses by australian architects and non-architects," in Proceedings of the Culture, Space, History. Sevki Vanh Foundation for Architecture, 1990.

[9] T. Purcell and J. L. Nasar, "Australian architect and non architect experiences of american houses," in Proceedings of the 11th International Congress on Empirical Aesthetics of the International Association of Empirical Aesthetics, 1990.

[10] A. E. Stamps, "Public preferences for high rise buildings: stylistic and demographic effects," Perceptual and Motor Skills, vol. 72, pp. 839-844, 1991.

[11] R. Gifford, D. W. Hine, W. Muller-Clemm, D. Reynolds, and K. Shaw, "Decoding modern architecture: a lens model approach for understanding the aesthetic differences of architects and laypersons," Environment and Behavior, vol. 32, no. 2, pp. 163$187,2000$.

[12] R. Gifford, D. W. Hine, W. Muller-Clemm, and K. T. Shaw, "Why architects and laypersons judge buildings differently: cognitive properties and physical bases," Journal of Architectural and Planning Research, vol. 19, no. 2, pp. 131-148, 2002.

[13] A. Akalin, K. Yildirim, C. Wilson, and O. Kilicoglu, "Architecture and engineering students' evaluations of house façades: preference, complexity and impressiveness," Journal of Environmental Psychology, vol. 29, no. 1, pp. 124-132, 2009.

[14] E. Brunswik, Perception and the Representative Design of Psychological Experiments, University of California, Berkeley, Calif, USA, 1956.

[15] D. E. Berlyne, Aesthetics and Psychobiology, Appleton-Century-Crofts, New York, NY, USA, 1971.

[16] J. L. Nasar, "Architectural symbolism: a study of house-style meanings," in Proceedings of the Paths to Co-existence of Environmental Design Research Association (EDRA '88), D. Lawrence and B. Wasserman, Eds., vol. 19, pp. 63-171, 1988.

[17] A. T. Purcell, "Environmental perception and affect: a schema discrepancy model," Environment and Behavior, vol. 18, pp. 330, 1986.

[18] A. T. Purcell, "The relationship between buildings and behaviour," Building and Environment, vol. 22, no. 3, pp. 215-232, 1987.

[19] A. T. Purcell and J. L. Nasar, "Experiencing other people's houses: a model of similarities and differences in environmental experience," Journal of Environmental Psychology, vol. 12, no. 3, pp. 199-211, 1992.

[20] P. Lewicki, T. Hill, and E. Bizot, "Acquisition of procedural knowledge about a pattern of stimuli that cannot be articulated," Cognitive Psychology, vol. 20, no. 1, pp. 24-27, 1988.

[21] L. W. Barsalou, "Ideals, central tendency, and frequency of instantiation as determinants of graded structure in categories," Journal of Experimental Psychology: Learning, Memory, and Cognition, vol. 11, no. 4, pp. 629-654, 1985.

[22] F. M. Dieleman and C. H. Mulder, "The geography of residential choice," in Residential Environments: Choice, Satisfaction and Behavior, J. I. Aragonés, G. Francescato, and T. Gärling, Eds., pp. 35-54, Bergin \& Garvey, South Hadley, Mass, USA, 2002.

[23] C. H. Mulder, "Housing choice: assumptions and approaches," Journal of Housing and the Built Environment, vol. 11, no. 3, pp. 209-232, 1996.

[24] I. G. Ellen and M. A. Turner, "Does neighborhood matter? Assessing recent evidence," Housing Policy Debate, vol. 8, no. 4, pp. 833-866, 1997.

[25] T. Gärling and M. Friman, "A psychological conceptualization of residencial choice and satisfaction," in Residential Environments: Choice, Satisfaction and Behavior, J. I. Aragonés, 
G. Francescato, and T. Gärling, Eds., pp. 55-80, Bergin \& Garvey, South Hadley, Mass, USA, 2002.

[26] M. Nagamachi, Kansei Engineering, Kaibundo, Tokyo, Japan, 1989.

[27] M. Nagamachi, "Kansei engineering: a new ergonomic consumer-oriented technology for product development," International Journal of Industrial Ergonomics, vol. 15, no. 1, pp. 3 11, 1995.

[28] K. Lynch, A Theory of Good City Form, MIT Press, Cambridge, Mass, USA, 1981.

[29] D. Appleyard, Livable Streets, University of California, Berkeley, Calif, USA, 1981.

[30] F. D. Jarvis, Site Planning and Community Design for Great Neighborhoods, Home Builder, Washington, DC, USA, 1993.

[31] R. Küller, "Architecture and emotions," in Architecture for People, B. Milkellides, Ed., pp. 87-100, Studio Vista, London, UK, 1980.

[32] R. Küller, "Environmental assessment from a neuropsychological perspective," in Environment Cognition and Action: An Integrated Approach, T. Gärling and G. W. Evans, Eds., pp. 111-147, Oxford University Press, New York, NY, USA, 1991.

[33] A. P. Field, Discovering Statistics Using SPSS, Sage, London, UK, 2nd edition, 2005.

[34] J. Terninko, Step-by-Step QFD: Costumer-Driven Product Design, St. Lucie Press, Florida, 1997.

[35] C. E. Osgood, G. J. Suci, and P. H. Tannenbaum, The Measurement of Meaning, University of Illinois Press, Urbana, Ill, USA, 1957.

[36] T. Jindo, K. Hirasago, and M. Nagamachi, "Development of a design support system for office chairs using 3-D graphics," International Journal of Industrial Ergonomics, vol. 15, no. 1, pp. 49-62, 1995.

[37] Y. Matsubara and M. Nagamachi, "Hybrid Kansei Engineering System and design support," International Journal of Industrial Ergonomics, vol. 19, no. 2, pp. 81-92, 1997.

[38] C. Llinares and A. F. Page, "Application of product differential semantics to quantify purchaser perceptions in housing assessment," Building and Environment, vol. 42, no. 7, pp. 2488 2497, 2007.

[39] B. Flury, Common Principal Components and Related Multivariate Models, John Wiley \& Sons, New York, NY, USA, 1988.

[40] A. Basilevsky, Statistical Factor Analysis and Related Methods: Theory and Applications, John Wiley \& Sons, New York, NY, USA, 1994.

[41] D. L. Streiner, "Starting at the beginning: an introduction to coefficient alpha and internal consistency," Journal of Personality Assessment, vol. 80, no. 1, pp. 99-103, 2003.

[42] S. Nagasawa, "Kansei evaluation using fuzzy structural modeling," in Proceedings of the 1st Japan-Korea symposium on kansei engineering-consumer oriented product development technology on Kansei engineering I, M. Nagamachi, Ed., pp. 119-125, Kaibundo, 1997.

[43] C. Llinares and A. F. Page, "Differential semantics as a Kansei Engineering tool for analysing the emotional impressions which determine the choice of neighbourhood: the case of Valencia, Spain," Landscape and Urban Planning, vol. 87, no. 4, pp. 247-257, 2008.

[44] T. R. Herzog, "A cognitive analysis of preference for urban spaces," Journal of Environmental Psychology, vol. 12, no. 3, pp. 237-248, 1992.

[45] R. Kaplan, "The role of nature in the urban context," in $\mathrm{Hu}$ man Behavior and Environment: Advances in Theory and Research, I. Altman and J. F. Wohlwill, Eds., vol. 6, pp. 127-162, Plenum Press, New York, NY, USA, 1983.
[46] J. L. Nasar, "Perception and evaluation of residential street scenes," in Environmental Aesthetics: Theory, Research and Applications, J. L. Nasar, Ed., pp. 228-253, Cambridge University Press, Cambridge, UK, 1988.

[47] J. L. Nasar, "The evaluative image of the city," Journal of the American Planning Association, vol. 56, no. 1, pp. 41-53, 1990.

[48] T. Jindo and K. Hirasago, "Application studies to car interior of Kansei engineering," International Journal of Industrial Ergonomics, vol. 19, no. 2, pp. 105-114, 1997.

[49] S. Ishihara, K. Ishihara, M. Nagamachi, and Y. Matsubara, "An analysis of Kansei structure on shoes using self-organizing neural networks," International Journal of Industrial Ergonomics, vol. 19, no. 2, pp. 93-104, 1997.

[50] Y. Shimizu and T. Jindo, "A fuzzy logic analysis method for evaluating human sensitivities," International Journal of Industrial Ergonomics, vol. 15, no. 1, pp. 39-47, 1995. 


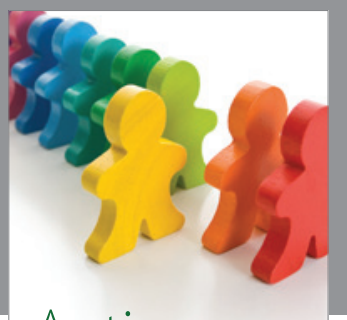

Autism

Research and Treatment
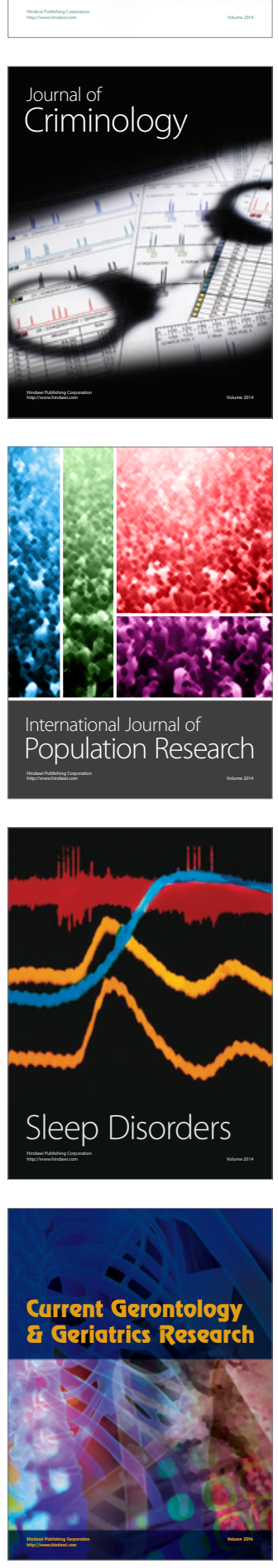
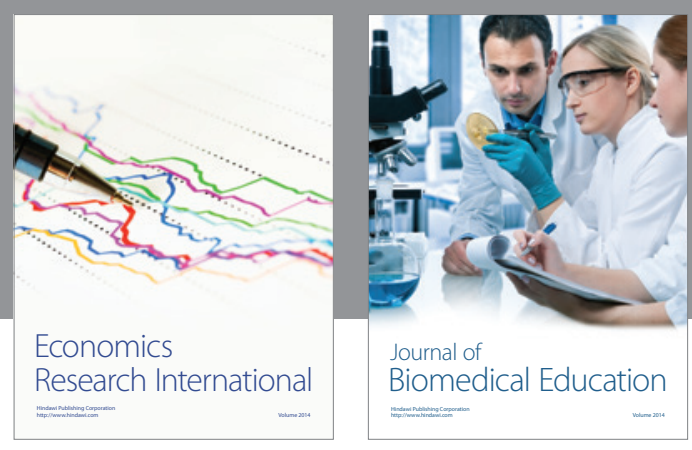

Journal of

Biomedical Education

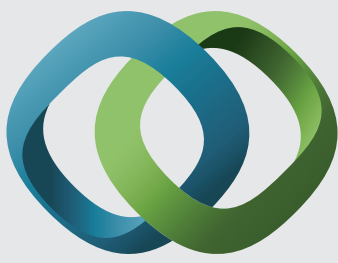

\section{Hindawi}

Submit your manuscripts at

http://www.hindawi.com
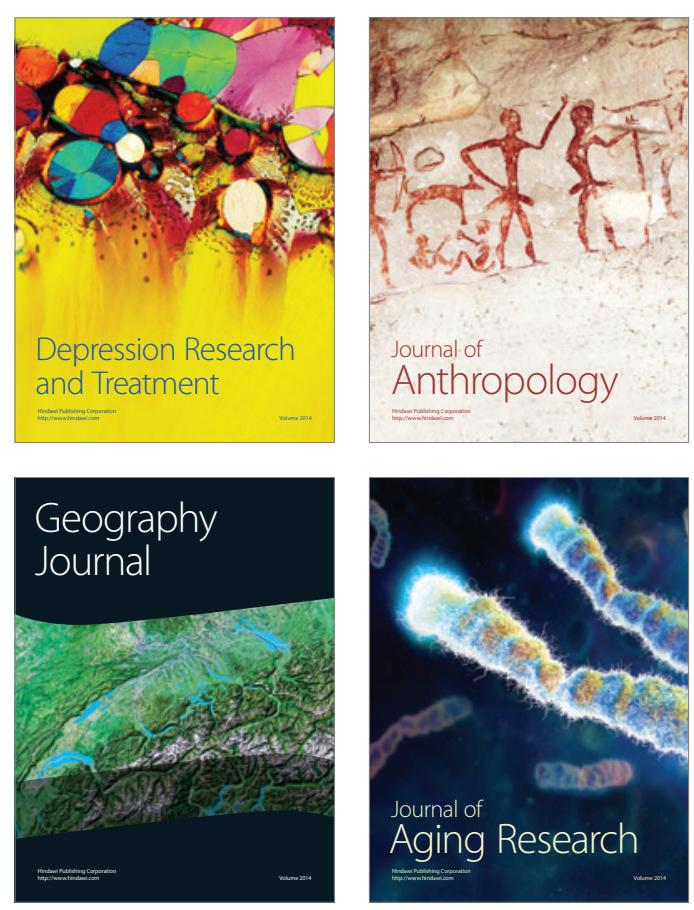

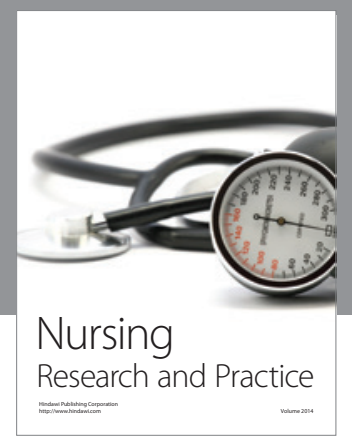

Nursing

Research and Practice

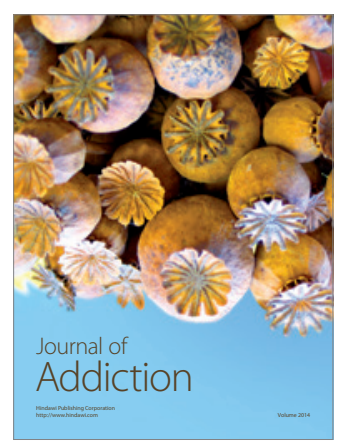

Child Development

Research

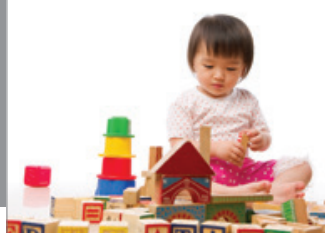

迥
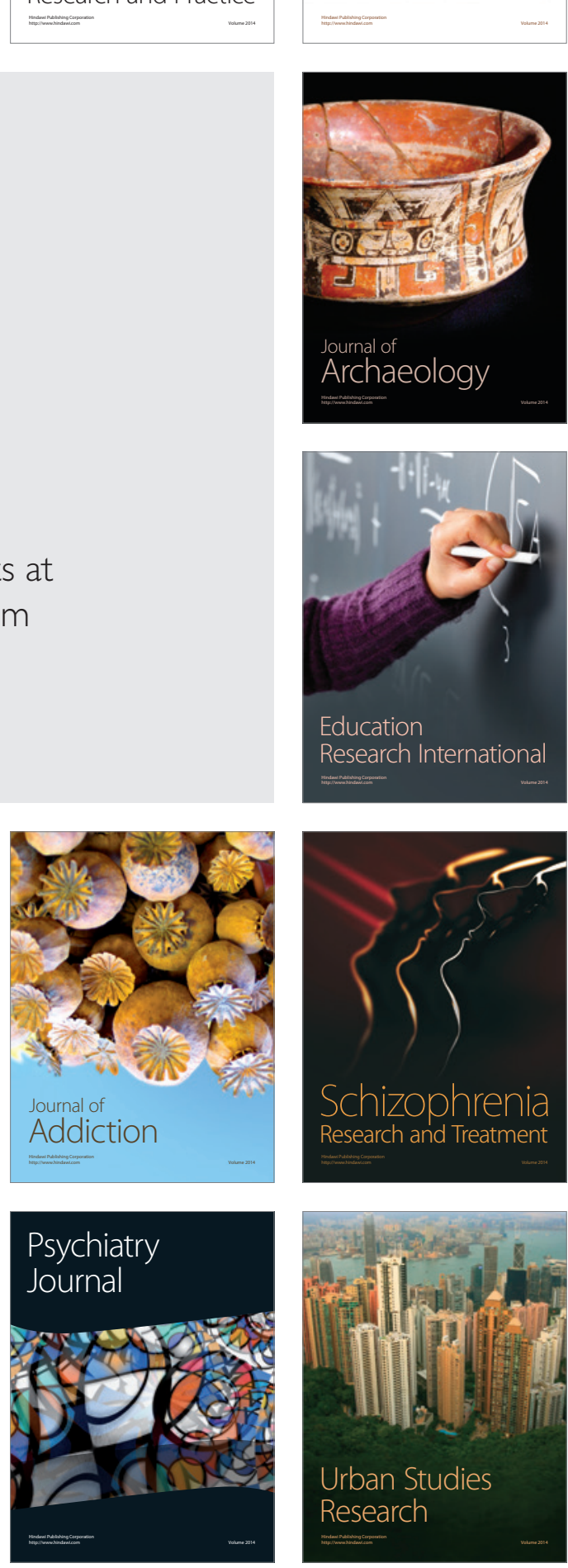